\title{
Do mais íntimo da experiência analítica ao mais público das políticas voltadas à saúde: um desafio ${ }^{1}$
}

\author{
Rogerio Lerner ${ }^{2}$
}

Quero inicialmente agradecer ao convite que me foi feito pela Audrey em nome da comissão organizadora deste importante evento. Pediram-me que contasse a respeito da experiência de trabalhar com profissionais do serviço público, principalmente das áreas de saúde e educação, com o propósito de tornar sua prática mais sensível a aspectos psíquicos das pessoas que são atendidas. Este tem sido, de maneira ampla, o foco do meu trabalho acadêmico como pesquisador há muitos anos. Isto se deve por vários motivos, iniciando-se pela importância que teve sobre mim a análise que comecei quando adolescente, que teve um enorme impacto na forma de eu perceber o mundo e de me perceber no mundo. Uma parte considerável do que tenho conseguido transformar, construir e também suportar da minha personalidade, decorre desta análise, bem como muitos dos aspectos identitários elaborados ao longo deste percurso. Não tenho dúvidas da influência desta experiência analítica na minha escolha por me tornar psicólogo.

Gostaria de destacar dois grandes grupos de experiências vividas em análise: em primeiro lugar, gostaria de mencionar situações muito pouco percebidas para além de intuições, o que as tornava difíceis de serem pensadas e aprofundadas, e muito fáceis de serem racionalizadas. Quando nomeadas e trabalhadas, em geral eu sentia a cada ciclo, por assim dizer, ao lado da frustração de ter de abrir mão de racionalizações e de idealizações, uma sensação de ampliação de significados, e também algo como uma espécie de consolidação de impressões até então vagas.

\footnotetext{
${ }^{1}$ Este trabalho foi apresentado na mesa "Diagnóstico precoce: quem, onde, como? " com Maria Cecilia Pereira da Silva no eixo "Psicanálise e suas clinicas" no I Simpósio Bienal "O mesmo, o outro: Psicanálise em movimento" da Sociedade Brasileira de Psicanálise de São Paulo.

${ }^{2}$ Membro Filiado da Sociedade Brasileira de Psicanálise de São Paulo, Prof. Associado (Livredocente) do IPUSP
} 
Em segundo lugar, gostaria de mencionar experiências sobre as quais eu não fazia a menor ideia de que pudessem existir, nem mesmo nutria por elas a mais vaga intuição. O processo que levava à realização destas experiências muitas vezes se dava de maneira surpreendente, frequentemente com vergonha, medo ou culpa.

Apesar de o percurso analítico ser extremamente trabalhoso, difícil e muitas vezes doloroso, ou talvez justamente por tudo isto, considero que isto marcou minha posição na vida como sendo a de uma inexorável e profunda apreciação da complexidade do inconsciente.

Estudei psicologia numa universidade pública que tem diversos serviços voltados para a comunidade. Muitos deles se dão sob a forma de estágio para alunos de graduação e outros são ofertados por docentes e psicólogos em diversos formatos de cursos voltados a servidores de equipamentos públicos principalmente das áreas de educação e saúde.

Um impasse passou a se formular na minha cabeça: como articular o que eu apreendia na minha análise pessoal e na formação em psicanálise sobre aspectos inconscientes da vida psíquica com a proposta de transformar a prática dos profissionais que demandavam formação da universidade? Todos aqui sabemos como são únicas e específicas as condições do setting analítico que concorrem para a ocorrência da experiência analítica e como são distintas das circunstâncias que se apresentam para trabalhar com profissionais do serviço público que buscam conhecimento para seu trabalho cotidiano.

Há ainda um elemento agravante ao impasse que acabei de anunciar: desde o final do século XIX, o campo dos conhecimentos em torno da saúde e da educação passou a contar com a produção científica e tem se tornado cada vez mais especializado. A demanda dos profissionais que acorrem à universidade para formação continuada é, assim, muitas vezes marcada por uma expectativa técnica. Querem saber o que fazer, com que tipo de paciente ou situação enfrentada, e que resultado produzir.

Quanto mais eu dava aulas, palestras e outras formas de transmissão do conhecimento, mais eu sentia que o que eu dizia ficava distanciado da prática dos profissionais; mais difícil de ser apropriado por eles. Eu via sentidos e relações profundas entre os conteúdos que transmitia e o que considerava motivações inconscientes, mas não era possível construir tais sentidos a partir da perspectiva deles. É como se não se construíssem os continentes necessários a partir de 
experiências emocionais e pessoais para que tais conteúdos alcançassem algum sentido significativo.

Um exemplo do desafio de transpor conteúdos relacionados ao entrelaçamento do desenvolvimento infantil aos aspectos inconscientes pode ser visto na fala de um médico que participou de um treinamento para uso de um instrumento chamado Indicadores Clínicos de Referência para o Desenvolvimento Infantil - IRDI (Lerner \& Kupfer, 2008), construído a pedido do Ministério da Saúde, financiado por ele e também pela FAPESP e pelo CNPq. O IRDI é um protocolo com 31 itens que podem ser observados e perguntados pelo profissional que atende crianças e pais nas primeiras consultas de puericultura; estes itens expressam situações favoráveis ao desenvolvimento psíquico infantil no vínculo do bebê de zero a dezoito meses com seus cuidadores. Ele foi construído a partir do conhecimento psicanalítico aliado ao de outras áreas, como psicologia do desenvolvimento, pediatria e fonoaudiologia. Em estudo de desenho epidemiológico, verificou-se que se a díade cuidador-bebê tem indicadores ausentes, isto representa uma dificuldade no desenvolvimento que pode estar associada a problemas futuros. Dependendo dos indicadores ausentes, a dificuldade atual e os problemas futuros podem ser mais ou menos preocupantes.

Após a validação do IRDI, foram feitos cursos de capacitação e treinamento para pediatras e outros profissionais de enfermagem, de creches, agentes comunitários do programa da saúde da família, dentre outros. Este médico foi entrevistado 6 anos após participar de um treinamento em formato tradicional, baseado em aulas expositivas concentradas em dois dias de curso, para uso do IRDI. A intensão ao entrevistá-lo era verificar em que medida ele retivera, mantinha e usava o conhecimento acerca da construção do psiquismo no vínculo com os cuidadores que lhe fora transmitido no curso.

Ficou evidente, pela análise da entrevista (Morais, Bronzatto, Lerner \& Kupfer, 2015), que o médico considerou que o treinamento foi importante para sua prática. $\mathrm{O}$ mais impactante para ele foi a situação de avaliar o bebê no vínculo com seus cuidadores, ao invés de avaliá-lo isoladamente em suas funções motoras e indicadores de saúde. A maneira como contava de seus atendimentos após o treinamento revelou mais liberdade e prazer em considerar e dar importância para o vínculo dos cuidadores com seus bebês em seu trabalho clínico. Entretanto, sua formação médica anterior levou-o a considerar, de maneira geral, o IRDI como mais um dentre vários instrumentos de avaliação de situações eventualmente patológicas não orgânicas decorrentes de hábitos parentais inadequados. Apesar da novidade, o formato acadêmico do 
treinamento não favoreceu uma apropriação do sentido mais profundo dos itens do IRDI na sua importância para a construção do psiquismo com seus mecanismos inconscientes que se expressam, por vias indiretas, ao longo do desenvolvimento.

Interessantemente, os indicadores mais marcantes para o médico entrevistado foram aqueles ligados à função paterna. Ele mesmo teceu a suposição, na entrevista, que isto deve ter se dado pelo fato de sua esposa ter engravidado justamente na época em que ele estava trabalhando com o IRDI. Temos aqui um exemplo de como a referência à experiência pessoal é importante para a apropriação de um sentido mais profundo do que é transmitido. Nas palavras do próprio médico: "talvez eu necessitasse disto [ele se referia ao conhecimento referente aos itens ligados à função paterna do IRDI] para me preparar como pai... E eu tento ser o pai mais participativo que eu posso".

Em trabalhos posteriores com profissionais de saúde e educação, passamos a fazer o treinamento para uso do IRDI num novo formato, menos acadêmico do que se fazia até então. Chamamos a nova proposta de oficinas de sensibilização para a importância de aspectos psíquicos do desenvolvimento. Dividimos a oficina em quatro encontros com intervalos de cerca de dois meses entre si, cada um com 4 horas de ocorrência.

Desde o primeiro encontro, nossa equipe buscou aproximar a teoria sobre os indicadores às vivências pessoais e profissionais dos participantes. Não queríamos criar uma hierarquização de saberes que dificultasse a apropriação do conteúdo transmitido e, portanto, iniciamos o trabalho com conhecimentos e experiências trazidos pelos participantes divididos em pequenos grupos mediados pelos pesquisadores. Enfocamos duas questões: em quais situações da vida os profissionais encontravam bebês; $\mathrm{O}$ que estes bebês mobilizavam nas pessoas (que sentimentos e lembranças eram despertados). Na segunda etapa do primeiro encontro, foi ministrada uma aula a respeito de algumas noções de desenvolvimento e dos fundamentos psicanalíticos e usos dos IRDI da primeira faixa etária do bebê (0-4 meses).

$\mathrm{Na}$ ficha de acompanhamento da oficina preenchidas após o encontro, foram relatadas “insatisfações quanto à estrutura da formação e ao estilo de transmissão. Os participantes demandavam modelos de curso vivenciados previamente, estruturados em forma de palestras temáticas. Ouvia-se: Não vimos nada de novo; Esperávamos mais” (Morais, 2013). 
No segundo encontro, quando abordamos a segunda faixa etária do IRDI, fizemos um ajuste para que houvesse aproximação da demanda dos participantes. Os comentários foram mais favoráveis do que após o primeiro encontro. Tivemos a hipótese de que isto se deveu a dois aspectos: além da ocorrência de um formato mais tradicionalmente esperado, como uma aula, este encontro ocorreu após termos explorado a experiência dos profissionais com o tema no primeiro encontro.

No terceiro encontro, os profissionais foram divididos novamente em grupos menores. Acompanhados por uma pessoa da equipe, cada grupo discutia dois indicadores da terceira faixa do IRDI, dava exemplos de sua ocorrência e propunha modificações nos enunciados e na descrição do indicador. No final, as propostas de todos os grupos eram discutidas abertamente em conjunto a fim de que se alcançasse consenso na sua formulação final e eram tecidas articulações entre os itens abordados e a teoria subjacente.

No quarto encontro, quando abordamos a quarta faixa do IRDI, repetimos o formato do terceiro, em que um primeiro momento de apropriação dos indicadores era feito em pequenos grupos e depois aberto à discussão e articulado à teoria com o grupo todo.

Ao final de cada encontro, os participantes relatavam exemplos de situações de uso do IRDI em sua prática e tiravam eventuais dúvidas que tivessem a respeito. Ao longo de todo o trabalho, pesquisadores da equipe acompanhavam e faziam encontros de discussão com os profissionais para trabalhar eventuais dúvidas e efeitos da aplicação do IRDI. Era frequente que profissionais relatassem aos pesquisadores aspectos de sua história mobilizados por esta experiência, muitas vezes dolorosos.

As vinhetas abaixo ilustram como as oficinas de sensibilização para a importância de aspectos psíquicos do desenvolvimento repercutiram sobre a prática dos profissionais (Lerner, Di Paolo, Campana, Morais, Tocchio \& Resegue, 2013).

Mariana, auxiliar de enfermagem, aplicava o IRDI quando a mãe disse que não dava alimentos inteiros (IRDI-22) para o bebê de 11 meses. Mariana perguntou a razão e a mãe contou que temia que a criança engasgasse. A profissional explicou que a criança tinha capacidade para chupar o alimento e que só assim ele poderia fortalecer a mandíbula. Comentou que a criança 
já deveria comer arroz, feijão, legumes amassados, carnes desfiadas e que era importante experimentar coisas diferentes das que estava acostumada para poder aprender a gostar delas.

$\mathrm{Na}$ aplicação da quarta faixa do protocolo, a criança veio em companhia da avó. Quando se perguntou se a criança comia bem, a avó contou que sim e que anteriormente, a mãe só dava comida batida, mas que recentemente introduziu alimentos amassados e em pequenos pedaços. A criança aceitou bem, comendo no mesmo prato que a mãe e a avó, costume cultural da região de fora de São Paulo de onde se originam.

A orientação feita por Mariana contemplou elementos pessoais da mãe ao levá-la a explicitar seu medo de o filho engasgar, ao mesmo tempo em que mencionou a necessidade de que ele pudesse experimentar as comidas de que viesse a gostar, permitindo que a mãe se apropriasse à sua maneira do que foi orientado. O compartilhamento do mesmo prato da mãe e da avó, elemento cultural de ligação pessoal, familiar e íntima, reforça a natureza pessoal do contato com o menino, dando- lhe a oportunidade de estar em uma posição diversa da que tinha até então, mais de acordo com suas necessidades de desenvolvimento.

Andrea é uma ACS com grande envolvimento no acompanhamento dos bebês, estando muito atenta a eles e discutindo as sutilezas que os indicadores do IRDI propõem. Em uma das famílias que visitou em companhia da psicóloga monitora, comentou a anotação do IRDI-12 (A mãe dá suporte às iniciativas da criança, sem poupar-lhe o esforço) como ausente. Ao detalhar sua observação, a ACS referiu-se a situações em que a mãe entregava tudo na mão da criança. Lembrou-se ainda que, na ocasião do nascimento do primeiro filho desta família, tal tendência materna pode ter influenciado no atraso na fala. Andrea cuidadosamente comentou a associação entre tais situações com a mãe, que respondeu que tinha dificuldades em antecipar as realizações da criança. A postura educativa que era característica das intervenções de Andrea encontra-se relativizada nessa situação, por escutar a mãe antes de prescrever uma ação e, ainda, pelo fato de que a intervenção descrita se deu sob forte transferência afetuosa com a ACS - evidenciada pelo tom carinhoso entre ambas e pelo conhecimento, por parte da profissional, de grande parte da rotina e modo de cuidado dessa mãe em relação a seus filhos. Na segunda aplicação do IRDI na mesma faixa desse bebê, o item 12 havia se tornado presente. 
De maneira geral, os profissionais que passam pelas oficinas dizem que, apesar de já intuírem que algumas das situações apontadas no IRDI são importantes para o desenvolvimento e que sua ausência significa dificuldades no vínculo entre cuidadores e bebês, não se sentiam confiantes para conversar a respeito em seus atendimentos. Contam que a experiência das oficinas é importante tanto por ser uma espécie de certificação científica do que já intuíam como também serve para aprofundar e ampliar o significado deste conhecimento. Há trabalhos ${ }^{5}$ que mostram que, antes das oficinas, a referência a aspectos do desenvolvimento pelos profissionais tem alta ocorrência de menções a vacinação, aleitamento e medição, ao passo que, após as oficinas, aumenta significativamente a menção espontânea a elementos referentes ao vínculo e à expressão das emoções pelos bebês e seus cuidadores. É frequente, também, que estes profissionais se tornem mais sensíveis para condições psíquicas parentais para as quais antes não prestavam atenção, como ansiedade e depressividade, que podem se expressar e influenciar o vínculo com o bebê.

Este trabalho é mais um exemplo da contribuição da psicanálise, em algumas das dimensões de sua ocorrência, para campos que se situam fora do seu enquadre clínico tradicional. Para que isto ocorra, sempre são necessárias transformações, renúncia a idealizações e tolerância a frustrações. Para mim, é uma forma de tentar construir constantemente uma articulação entre o mais íntimo da experiência analítica com o mais público das políticas voltadas à saúde e à educação em nosso país.

\section{Referências}

Lerner, R; Di Paolo, AF; Campana, N; Morais, AS; Tocchio, AB; Resegue, R. (2013). Uma contribuição da Psicanálise para a Saúde Coletiva: Protocolo de Indicadores Clínicos de Risco para o Desenvolvimento Infantil. Revista LatinoAmericana de Psicanálise, 1, 226-237.

Lerner, R.; Kupfer, M.C.M. (Org.). (2008). Psicanálise com crianças: Clínica e pesquisa. São Paulo, SP: Escuta.

Morais, A. S. (2013). Usos e apropriações de indicadores clínicos de risco para o desenvolvimento infantil por agentes comunitários de saúde: uma experiência de formação. Dissertação de Mestrado, Instituto de Psicologia, Universidade de São 
Paulo, São Paulo. doi:10.11606/D.47.2013.tde-30072013-122005. Recuperado em 2018-07-29, de www.teses.usp.br

Morais, AS; Bronzatto, EM; Lerner, R \& Kupfer, MC. (2015). Effects of Pediatric Training for Detecting Signs of Developmental Problems. Psicologia: Ciência e profissão, 35(2), 359-373.

Tocchio, A. B. (2013). Educação permanente de profissionais de enfermagem da atenção básica à saúde a partir de Indicadores Clínicos de Risco para o Desenvolvimento Infantil. Dissertação de Mestrado, Instituto de Psicologia, Universidade de São Paulo, São Paulo. doi:10.11606/D.47.2013.tde-30072013120530. Recuperado em 2018-07-29, de www.teses.usp.br 